\title{
PSYCHOLOGY STUDENTS' PERCEPTIONS ON THEIR QUALITY OF LIFE DURING COVID-19 PANDEMIC
}

\author{
Maria Claudia Ionescu ${ }^{1 *}$, Andreea Stan ${ }^{1}$ \\ ${ }^{1}$ University of Piteşti, Department of Psychology, Communication Sciences, and Social Work, \\ Târgul din Vale, No.1, 110040, Piteşti, Argeş County, Romania
}

\section{Current Trends in}

\section{Natural Sciences}

\begin{abstract}
The COVID-19 pandemic has affected many lives and has a considerable social and economic impact. In response to this crisis, governments have implemented a series of protection measures: lockdown, social distancing, wearing a mask etc. Studies and statistics on the effects of the COVID-19 pandemic indicate low levels of mental and physical well-being, depression, fear of uncertainty, increasing inequality due to job loss, increased stress due to financial matters, social isolation etc.

The current study has two main objectives: to explore Psychology students 'perceptions on changes in their quality of life, by comparing two periods of time: before and during COVID-19 pandemic and to identify differences in students' perceptions on changes in their quality of life, according to their COVID-19 disease status. We designed a questionnaire including different aspects of quality of life, based on WHO Quality of Life - Bref (WHOQOL-BREF) (2004). Results have indicated that the main changes are related to opportunities for leisure activities, ability to concentrate, ability to perform daily living activities, mobility, capacity for work, feeling safe, and having enough money.
\end{abstract}

Keywords: COVID-19, Psychology students' perceptions, Quality of Life

\section{INTRODUCTION}

Quality of Life (QoL) is defined as "an individual's perception of their position in life in the context of the culture and value systems in which they live and in relation to their goals, expectations, standards and concerns" (World Health Organization - WHO, 1998).

It is important not to confuse quality of life with standard of living (wealth and material comfort) (Skevington, 2007).

The definitions of QoL vary among authors, but there is agreement that it is a multidimensional construct. QoL is a subjective evaluation and it comprises the following dimensions (World Health Organization - WHO, 1998): physical health, psychological state, level of independence, social relationships, personal beliefs, relationships to salient features of the environment. Examples of things that increase the quality of life at the individual level are: "higher pay, longer holidays, more satisfaction in our working lives, time to pursue enjoyable and satisfying leisure pursuits; emotional fulfilment in our relationships, and having a long healthy and happy life, all lived within a safe, caring and supportive local community" (Phillips, 2006, p. 3). Research shows that QoL is associated with lower mortality risk in the general population (Phyo et al., 2020), positive emotions 
and life satisfaction. Younger ages, higher levels of education and higher socioeconomic levels are associated to better QoL (Patrício et al., 2014).

In this study, we approach changes in the quality of life in the context of the COVID-19 pandemic. COVID-19 is the disease caused by SARS-CoV-2 (severe acute respiratory syndrome coronavirus 2), a virus that first appeared in Wuhan, China, in December 2019. The rapid spread of this virus worldwide, the large number of deaths among the elderly population and people with comorbidities, health problems resulting from the disease in people who survived, uncertainty about medical treatment, the absence of a vaccine caused a crisis in the public health system, the World Health Organization declaring the novel coronavirus (COVID-19) outbreak a global pandemic, on March 2020. To respond to this crisis, governments have taken a number of protection measures: lockdown, social distancing, wearing a mask, quarantine and isolation for those infected etc. Although beneficial in suppressing the rapid spread of the virus, these measures have also had a negative impact on the quality of life of individuals. In addition, the appearance of the vaccine has generated a number of concerns and distrust about side effects in some vulnerable people.

The study of the impact that the COVID-19 pandemic and the measures taken to prevent the spread of the virus have on the quality of life of the population highlights a series of negative effects, especially at the beginning of the pandemic.

Negative psycho-emotional conditions (anxiety, depression, fear of COVID-19, poor subjective sleep quality) were found among university students in Bangladesh, during the early period of the pandemic (April 2020) (Ahammed et al., 2021); concerns in the general population in the Kingdom of Saudi Arabia about health and job loss enhance the risk for anxiety and stress, authors stressing the importance of organizational support for employees facing major changes in working conditions in the context of limited teleworking experience (Algahtani et al., 2021); Qiu et al. (2020) identified higher scores of distress among the young adults (this category of population accesses a large amount of information from social media) and people with higher education who, according to the authors, probably have a higher level of health related self-awareness. However, the authors note that as time passes, the level of distress decreased significantly, highlighting the role of prevention and control measures taken by the Chinese Government. Higher levels of distress were found also in a study with undergraduate and post-graduate students from Qatar University (from 11 June to 11 July 2020), subjects reporting that they are less inspired and determined; however, the authors did not identify correlations between social distancing and any of the four domains of QoL (physical health, psychological health, social relationships, and environment) (Megreya et al., 2021). Mental health was also affected by disruption of daily activities due to lockdown. Cruyt et al. (2021) identified a positive relation between lack of meaningful activities and reduced mental health among Belgian adults aged 18 years or older during COVID-19 restrictions.

Leong Bin Abdullah, Murad. Teoh, \& Mohamad (2020), in an online survey investigating 316 Malaysian university students' QoL and its association with various factors and social support during the COVID-19 pandemic, found out that a greater number of hours of online classes attended per week and higher family and friend support significantly predicted an increase in physical health quality of life among the respondents and that frustration caused by study disruption and higher severity of stress symptoms significantly predicted a decrease in physical health QoL. The difficulties experienced by the participants (uncertainty about their future as their study was prolonged, their graduation time would be delayed as a result of the COVID-19 pandemic and the loss of their daily academic routine) were associated with increased severity of stress symptoms. 
Other studies investigated the changes in cognitive functioning during COVID-19 pandemic. Fiorenzato et al. (2021) identified a correlation between imposed lockdown restrictions and subjective cognitive functioning, namely female gender, younger age and home confinement were risk factors of cognitive worsening (attention, temporal orientation and executive functions). The same study found that individuals working from home reported cognitive worsening, but not individuals working outside home.

COVID-19 lockdown imposed working from home for certain categories of the population. This change has generated both positive and negative experiences. Chung et al. (2020) report the results of a survey of UK employees on the impact of working from home on work-life balance. Subjects point to positive aspects such as: more time for family and housework, and more work done at home. Among the negative aspects are mentioned: blurred boundaries between work/home (due to school closure mothers allocated more time to the children's education, which affected the time allocated to work), lack of equipment and space to work, missing interactions with colleagues.

Measures to prevent the spread of the virus have also been adopted in Romania. In March 2020, a state of emergency was established throughout the country, restaurants and other public places were closed, cultural, scientific, artistic and other events held in closed spaces were suspended, home isolation or quarantine was required for people suspected of being infected, traffic restrictions were imposed, educational institutions were closed, and courses were held online. One year after the declaration of state of emergency, in higher education the courses are mostly online, with students returning to face-to-face activities only for laboratories and practical work.

\section{MATERIALS AND METHODS \\ Objectives}

The current study has two main objectives:

- to explore Psychology students' perceptions on changes in their QoL, by comparing two periods of time: before and during COVID-19 pandemic;

- to identify differences in students' perceptions on changes in their QoL, according to their

\section{Participants} COVID-19 disease status.

Our sample included 106 Psychology students, 97 (91.5\%) females and $9(8.5 \%)$ males, with ages between 19 and $54(\mathrm{M}=30, \sigma=10.62) .83(78.3 \%)$ are Bachelor degree students and $23(21.7 \%)$ are Master's degree students. $42(39.6 \%)$ of them are Freshmen, $41(38.7 \%)$ are Sophomores, and 23 $(21.7 \%)$ are Senior students. 59 (55.7\%) are employed and 57 (44.3\%) are unemployed. 37 (34.9\%) had contracted COVID-19.

\section{Measure}

We designed a online survey questionnaire including:

- 26 items based on WHO Quality of Life - Bref (WHOQOL- BREF) (2004). Each item represents an aspect of quality of life.

- one question about the positive/negative quality of the changes in different quality of life aspects.

- sociodemographic data (gender, age, year of study, type of program, COVID-19 disease status, employment status).

We asked students how much each of these 26 aspects has changed (comparison between two moments: before and during COVID-19 pandemic)? They could choose one answer from a Likert- 
type response scale (Very little, A little bit, Undecided, A lot, Very much, N/A). We also asked how was the quality of the changes? The response scale included: Very negative, Rather negative, Neither negative or positive, Rather positive, Very positive, Both negative and positive. WHO Quality of Life - Bref includes 26 quality of life aspects in four domains:

- Physical health: dependence on medicinal substances, energy, mobility, pain, sleep and rest, ability to perform daily activities, work capacity;

- Psychological: body appearance, negative feelings, self-esteem, life meaning, life enjoyment, concentration ability;

- Social relationships: personal relationships, social support, sexual activity;

- Environment: financial resources, physical safety and security, quality of health care services, home environment, availability of information, opportunities for recreation / leisure activities, physical environment, transport.

\section{RESULTS AND DISCUSSIONS}

Figure 1 indicates the percentages of students who perceive that the changes related to different aspects of their QoL are big and very big, comparing the present situation and the time before the COVID-19 pandemic.

As we can see, more than $30 \%$ of our respondents say that the main changes are related to opportunities for leisure activities (38.7\%), concentration ability (33\%), ability to perform daily activities (33\%), mobility (33\%), work capacity (32.1\%), financial resources $(31.2 \%)$, and physical safety and security (31.1\%). $25.5 \%$ of students said that their overall quality of life has changed.

Less than $20 \%$ of our respondents reported big differences regarding their home environment (19.8\%), sexual activity (18.9\%), physical pain (15.1\%), health status (14.2\%), and medical treatment $(9.5 \%)$.

The management of COVID-19 pandemic forced governments to impose restrictive measures (lockdown, mobility restrictions, work from home, social distancing etc.), that interfered with our normal living. That is why in Psychology students' perception, the main changes were related to opportunities for leisure activities (theatres, cinemas, gyms, clubs, restaurants, social gathering spaces were closed for long periods of time), ability to perform daily activities (the lockdown confined people in their homes, allowing them to go out only under certain conditions, legally imposed), mobility (freedom of movement was also restricted).

Another important change is related to concentration ability. Online education put students in a new situation: attending classes from home or even from work (more than half of them are employed) means dealing with many potential distracting stimuli (accomplishing job assignments, parents presents in the house, kids attending online classes, significant other working from home). Another cause for our affected concentration ability during the pandemic is related to changes in our daily routine, which requires learning to do things in new ways. Online education means learning to deal with computer technology, Internet access, online educational platforms, which were new for some of the students, especially the older ones and even acquiring a computer, a tablet or a smartphone. This is an extra-load for our cognitive abilities, like working memory, which has a limited capacity. Concentration ability is affected also by stress and its negative emotional consequences like anxiety. This pandemic brought a lot of stress in our life. The uncertainty, the threat of catching the virus, the alarming daily news about deaths by COVID-19, the restrictive measures legally imposed, the potential or real job loss, fewer financial resources were all sources of stress. 


\section{Current Trends in Natural Sciences}

Vol. 10, Issue 19, pp. 105-112, 2021

https://doi.org/10.47068/ctns.2021.v10i19.014

Current Trends in Natural Sciences (on-line)

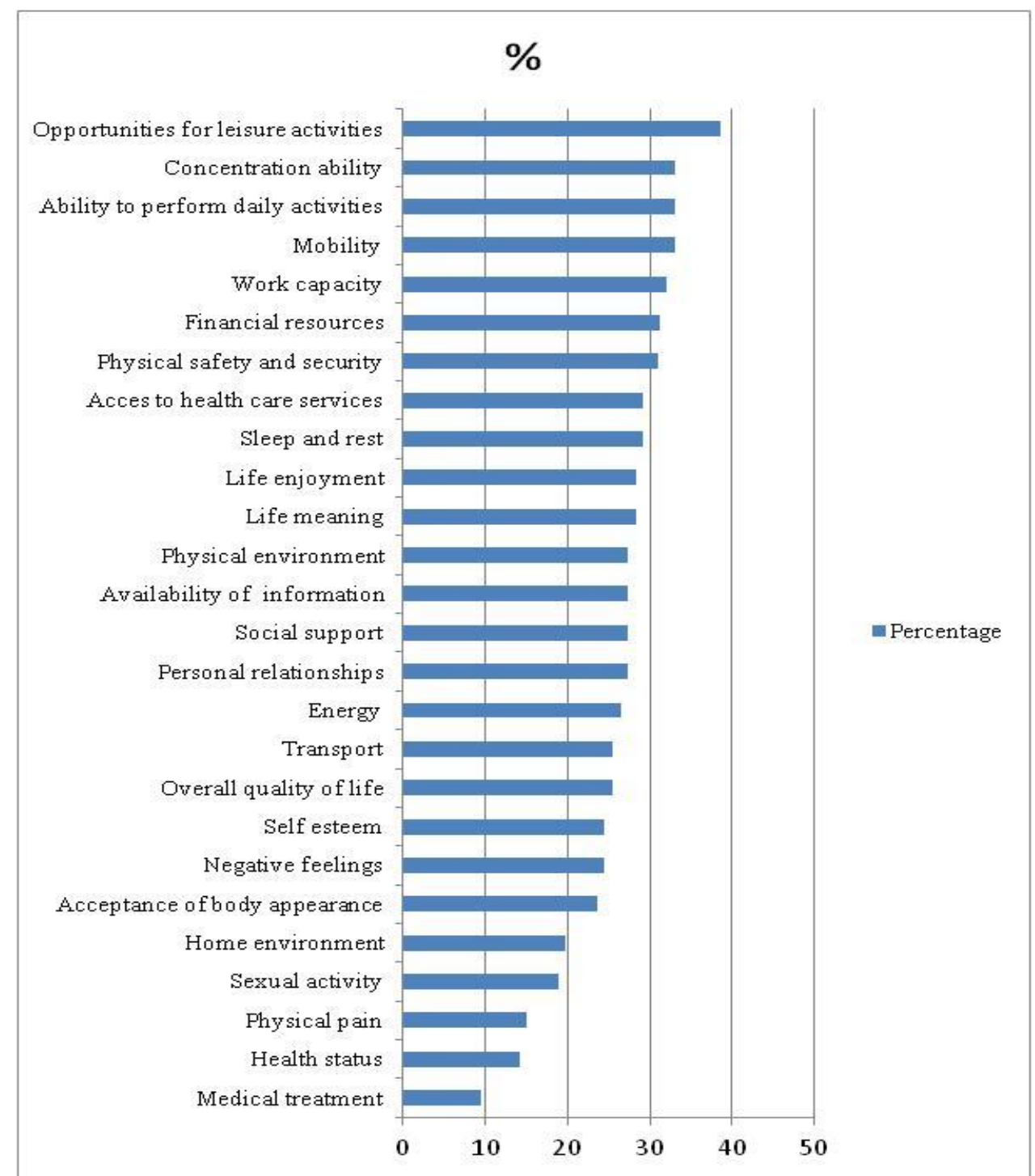

Figure 1. Changes in aspects of quality of life in students' perceptions

The concentration difficulty could affect students' work capacity. Another explanation for students' perception related to changes in work capacity could be linked to an increased load in academic assignments, especially in the first months of online education (March-May 2020), which many students complained about. Teachers didn't receive any institutional support in adapting to online education, so they found different ways of approaching online classes. Some of them followed the classes schedule already in place for the second term and used platforms that allowed interactive teaching like Skype or Zoom, others used the e-learning platform of the university in order to send and receive students' assignments.

These results are consistent with other research findings. Son et al. (2020) show that students at a public university in the United States reported difficulty in concentrating (various sources of distraction at home, home environment not conducive to studying), increased concerns on academic performance due to challenges of online classes, health related worry (about their own and their 


\section{Current Trends in Natural Sciences}

Vol. 10, Issue 19, pp. 105-112, 2021

https://doi.org/10.47068/ctns.2021.v10i19.014

Current Trends in Natural Sciences (on-line)

loved ones), negative impact on mental health due to lack of outdoor activities, financial difficulties (their own or their parents'), fewer opportunities for part-time jobs or internships

Regarding financial resources, this pandemic has affected many people who lost their jobs or had received decreased salaries. Some of the students were forced to go home because the campus was closed, leaving their part-time or full-time jobs, or they had to rent a house, which increased their living costs. For other students, lower income for their parents involved lower financial resources for them.

The high probability of caching SARS-CoV-2 was a permanent threat to our physical safety and security, especially in the first month of the pandemic.

When asked about the quality of these changes related to different aspects of their quality of life (table 1), $28.3 \%$ see them as very and rather negative, $46.2 \%$ as neither negative or positive, $10.4 \%$ rather and very positive and $15.1 \%$ both negative and positive.

Table 1. The quality of the changes (positive/negative)

\begin{tabular}{|l|l|r|r|r|r|}
\hline \multicolumn{2}{|c|}{ How were the changes? } \\
\hline \multirow{2}{*}{ Valid } & Frequency & Percent & Valid Percent & $\begin{array}{c}\text { Cumulative } \\
\text { Percent }\end{array}$ \\
\cline { 2 - 6 } & Very negative & 3 & 2.8 & 2.8 & 2.8 \\
\cline { 2 - 6 } & Rather negative & 27 & 25.5 & 25.5 & 28.3 \\
\cline { 2 - 6 } & Neither negative or positive & 49 & 46.2 & 46.2 & 74.5 \\
\cline { 2 - 6 } & Rather positive & 6 & 5.7 & 5.7 & 80.2 \\
\cline { 2 - 6 } & Very positive & 5 & 4.7 & 4.7 & 84.9 \\
\cline { 2 - 6 } & Both negative and positive & 16 & 15.1 & 15.1 & 100.0 \\
\cline { 2 - 6 } & Total & 106 & 100.0 & 100.0 & \\
\hline
\end{tabular}

Almost half of the students $(46.2 \%)$ say that the changes were neither negative or positive and almost a third $(28.3 \%)$ reported the changes to be very and rather negative. This could be the result of students' adaptation to the present situation, after more than a year since the pandemic was declared by WHO. Another explanation could be related to the fact that many restrictions imposed by the authorities in order to limit the sped of the virus were lifted in the moment of data collection, which could have a positive effect on students' perceptions, taking into consideration the recency effect.

We found that the biggest differences in perceptions of changes (table 2) for the two groups of students (those who had suffered and those who hadn't suffered from COVID-19) are related to access to health services and overall quality of life. $21.6 \%$ of those who contracted the virus and $33.3 \%$ from those who didn't contract the virus say that the access to health services had changed a lot and very much. The main effort in the health care system was focused on COVID-19 patients, which led to limited access to medical care for other patients.

$21.7 \%$ of the students who didn't get the disease and $32.4 \%$ of those who had it say that their overall quality of life has changes a lot and very much. We asked students to assess the quality of changes globally, for all the aspects included in quality of life, so we cannot say with certainty if this change in their overall quality of life is negative or positive. In line with other research on this subject, we can assume that the change is negative. 
Current Trends in Natural Sciences

Vol. 10, Issue 19, pp. 105-112, 2021

https://doi.org/10.47068/ctns.2021.v10i19.014

Current Trends in Natural Sciences (on-line)

Table 2. Perceptions on access to health services and overall quality of life according to SARS-CoV-2 infection status

\begin{tabular}{|l|l|r|r|}
\hline \multirow{2}{*}{\multicolumn{2}{|c|}{}} & \multicolumn{2}{|c|}{$\begin{array}{r}\text { Did you suffer from COVID-19 } \\
\text { disease? }\end{array}$} \\
\cline { 3 - 4 } & & No & \multicolumn{1}{c|}{ Yes } \\
\cline { 3 - 4 } access to health services & Very little & $21.7 \%$ & $27.0 \%$ \\
\cline { 2 - 4 } & A little bit & $18.8 \%$ & $24.3 \%$ \\
\cline { 2 - 4 } & Undecided & $14.5 \%$ & $21.6 \%$ \\
\cline { 2 - 4 } & A lot & $\mathbf{1 1 . 6 \%}$ & $\mathbf{1 0 . 8 \%}$ \\
\cline { 2 - 4 } & Very much & $\mathbf{2 1 . 7 \%}$ & $\mathbf{1 0 . 8 \%}$ \\
\cline { 2 - 4 } & N/A & $11.6 \%$ & $5.4 \%$ \\
\hline overall quality of life & Very little & $23.2 \%$ & $10.8 \%$ \\
\hline & A little bit & $30.4 \%$ & $18.9 \%$ \\
\hline & Undecided & $23.2 \%$ & $35.1 \%$ \\
\hline & A lot & $\mathbf{1 3 . 0 \%}$ & $\mathbf{1 6 . 2 \%}$ \\
\hline & Very much & $\mathbf{8 . 7 \%}$ & $\mathbf{1 6 . 2 \%}$ \\
\hline & N/A & $1.4 \%$ & $2.7 \%$ \\
\hline
\end{tabular}

\section{CONCLUSIONS}

Our survey investigated Psychology students' perceptions on changes in several aspects of their quality of life by comparing two periods of time: before and during COVID-19 pandemic and also differences in students' perceptions on these changes, according to their COVID-19 disease status. Our results indicated that the main change are related to opportunities for leisure activities, concentration ability, ability to perform daily activities, mobility, work capacity, financial resources, and physical safety and security. $25.5 \%$ of students said that their overall quality of life has changed. Almost a third (28.3\%) reported the changes to be very and rather negative.

Comparing the perceptions of the two groups (students who had the disease and those who hadn't), the biggest differences are related to access to health care services and overall quality of life.

The implications for practice of these results are linked to finding solutions for dealing with the changes in our quality of life. Some things like legal restrictions are not under our control, so our challenge is to find ways to adapt to this new and provoking situation. Adaptive solution at an individual level can include: finding a new daily routine, using time planning techniques, engaging in relaxing/leisure activities, seeking social support from friends and family, limiting distractors stimuli.

Future research in this area could investigate personal and social resources helpful in coping with the type of constraints imposed during COVID-19 pandemic and means people and institutions could use in order to improve their quality of life in the context of such threats.

The main limitation of our survey consists in the small study sample. We cannot extend our finding to all Psychology students. Another limitation of the study is related to the big numerical difference of the two groups (those who have contracted -34.9\%- and those who had not contracted COVID-19 $-65.1 \%$ ), so we should take this into consideration when we compare their perceptions.

\section{REFERENCES}

Ahammed, B., Jahan, N., Seddeque, A., Hossain, T., Shovo, T. E. A., Khan, B., Mamun, M. A., Islam, N. (2021). Exploring the association between mental health and subjective sleep quality during the COVID-19 pandemic among Bangladeshi university students. Heliyon, 7 (5), 1-8. 


\section{Current Trends in Natural Sciences}

Vol. 10, Issue 19, pp. 105-112, 2021

https://doi.org/10.47068/ctns.2021.v10i19.014

Current Trends in Natural Sciences (on-line)

ISSN: 2284-953X

Current Trends in Natural Sciences (CD-Rom)

ISSN: 2284-9521

ISSN-L: 2284-9521

ISSN-L: 2284-9521

Algahtani, F.D., Hassan, S.-u.-N., Alsaif, B., Zrieq, R. (2021). Assessment of the Quality of Life during COVID-19 Pandemic: A Cross-Sectional Survey from the Kingdom of Saudi Arabia. Int. J. Environ. Res. Public Health, 18, 847.

Chung, H., Seo, H., Forbes, S., Birkett, H. (2020). Working from home during the COVID-19 lockdown: changing preferences and the future of work. University of Kent.

Cruyt, E., De Vriendt, P., De Letter, M., Vlerick, P., Calders, P., De Pauw, R., Oostra, K., Rodriguez-Bailón, M., Szmalec, A., Merchán-Baeza, J. A., Fernández-Solano, A. J., Vidaña-Moya, L., Van de Velde, D. (2021). Meaningful activities during COVID-19 lockdown and association with mental health in Belgian adults. BMC Public Health, 21(1), 622.

Fiorenzato, E., Zabberoni, S., Costa, A., Cona, G. (2021). Cognitive and mental health changes and their vulnerability factors related to COVID-19 lockdown in Italy. PLoS ONE 16(1).

Leong Bin Abdullah, M.F.I., Murad, N.S., Teoh, S.H., \& Mohamad, M.A. (2020). Quality of life of university students during the COVID-19 pandemic: Assessing the level of quality of life and the associated factors after the end of movement lockdown. DOI: https://doi.org/10.21203/rs.3.rs-104496/v2. Retreived June 2, 2021, from https://assets.researchsquare.com/files/rs-104496/v2/ffeb0b81-7349-4ed1-9518-dd1598a5f73c.pdf.

Megreya, A.M., Latzman, R.D., Al-Ahmadi, A.M., Al-Dosari, N.F. (2021). The COVID-19-Related Lockdown in Qatar: Associations Among Demographics, Social Distancing, Mood Changes, and Quality of Life. International Journal of Mental Health and Addiction, 1-17.

Patrício, B., Jesus, L., Cruice, M., Hall, A. (2014). Quality of Life Predictors and Normative Data. Social Indicators Research, 119(3), 1557-1570.

Phillips, D. (2006). Quality of Life, Concept, Policy and Practice. London: Routledge.

Phyo, A.Z.Z., Freak-Poli, R., Craig, H., Gasevic, D., Stocks, N. P., Gonzalez-Chica, D. A., Ryan, J. (2020). Quality of life and mortality in the general population: a systematic review and meta-analysis. BMC Public Health, 20, 1596.

Qiu, J., Shen, B., Zhao, M., Wang, Z., Xie, B., Xu, Y., (2020). A nationwide survey of psychological distress among Chinese people in the COVID-19 epidemic: implications and policy recommendations. General Psychiatry: 33 (2).

Skevington, S. M. (2007). Quality of Life. In G. Fink, A. Stepto, eds, Encyclopedia of Stress (pp. 317-319). Amsterdam; Boston: Elsevier/Academic Press.

Son, C., Hegde, S., Smith, A., Wang, X., Sasangohar, F. (2020). Effects of COVID-19 on College Students' Mental Health in the United States: Interview Survey Study. Journal of medical Internet research, 22(9).

World Health Organization (1998). WHOQOL User Manual. Division of mental health and prevention of substance abuse.

World Health Organization (2004). The World Health Organization Quality of Life (WHOQOL)-BREF. 